\title{
Introduction: regional innovation systems and regional innovation policies
}

\section{Manuel González-López and Bjørn T. Asheim}

During the last two decades interest in regional innovation policies has progressively increased within the field of regional innovation studies. Such growing interest, which has been mostly European, is observed in the pattern of mentions of the term "regional innovation policy" in scientific papers (González-López et al. 2019).

Regional innovation policies studies are narrowly linked to the regional innovation system (RIS) approach (Cooke 1992; Cooke et al. 1997; Asheim and Isaksen 1997; Howells 1999; Asheim and Gertler 2005). The RIS approach, which emerged in the 1990s, linked to both the Innovation Systems (IS) literature and contemporary contributions on Economic Geography and Cluster Theory. The IS approach underlines that nations, regions and sectors show distinctive patterns of innovation, due to diverse technological and institutional trajectories (Lundvall 1992; Edquist 1997). Linked to the post-Schumpeterian views of the Evolutionary School (Nelson and Winter 1982; Dosi and Nelson 1994), innovation and economic changes are understood as a dynamic and path-dependent process, which contributes to explaining why each sector or territory follows different innovation trajectories, shaping different systems of innovation. Moreover, the IS literature draws also on the so-called "interactive learning theories" (Lundvall and Johnson 1994), where innovation is understood as a phenomenon that is the result of multiple interactions and continuous learning processes in which multiple agents participate. At the regional or national level, firms, higher education institutions or technological centres (among others) are the relevant agents that interact and give rise to learning processes and innovations.

The other basis for the RIS approach concerns several Economic Geography schools that, particularly since the 1980s, have emphasised the importance of innovation for regions' and territories' competitiveness. Among others, we can include here the New Industrial Districts school (Becattini 1990), the Flexible Production Systems approach (Scott 1988; Storper and Harrison 1991) and the Learning Region approach (Asheim 
1996; Morgan 1997). All these perspectives highlight the distinctive character of the factors influencing regional development (institutions, technologies, external connections, etc.). A similar perspective is also present in Cluster Theory, developed particularly by Porter, which has also served to influence both the RIS approach and regional innovation policies (Porter 2000; Cooke 2001). From these perspectives, each territory not only shows a particular economic trajectory, but also demands specific and place-based policies.

Unlike neoclassical economics, the Evolutionary and IS approaches are not only focused on market failures in order to underpin S\&T (Science \& Technology) policies, based on a linear view of innovation. Rather, they also focus on the need to address systemic failures based on the understanding that learning processes needed for innovation are the result of multiple interactions in systems where different agents and institutions are involved (Metcalfe and Georghiou 1997). Such interactions, for instance between universities and industries, are not always fluid and sometimes they do not even exist. When this happens, a policy intervention is needed.

Therefore, the systemic approach leads to other kinds of innovation policies, which are different and more complex. There is a broad range of different instruments that attempt to strengthen interactions and support the creation and expansion of innovative enterprises. Among them, it should be highlighted, are support infrastructures for innovation, such as technological parks and technological centres, in addition to the provision of services by innovation centres or agencies for innovation. Another relevant issue is the fostering of cooperation among the different elements and players involved in innovation, as well as the articulation and coordination of the IS. In this sense, the structures that encourage cooperation, mainly between enterprises and universities, are useful tools (collaborative projects, researchers' mobility, etc.). Interactions with the financing system are relevant as well.

\section{SMART SPECIALISATION STRATEGIES AND PATH TRANSFORMATION}

The dominant paradigm for regional innovation policies in recent times has been, at least in Europe, the so-called Smart Specialisation (SS) approach. As indicated by Bjørn Asheim (2019), the SS approach is coherent with the RIS approach and somehow a logical extension of it. In fact, it can be considered a natural link between regional development policies and innovation policies. SS refers to "the capacity of an economic system (a region for example) to generate new specialities through the 
discovery of new domains of opportunity and the local concentration and agglomeration of resources and competences in these domains" (Foray 2014, p. 1). Meanwhile Smart Specialisation Strategies (S3) refers to those actions and measures (policies) that promote this kind of process. As noted by McCann (2015, p.175), "the smart specialization logic argues that in order to foster innovation and growth regions should aim to prioritise those activities fostering and enhancing entrepreneurial search initiatives in activities which are aimed at technologically diversifying those activities which are both highly embedded within a region and also highly connected to other regions".

SS became a key pillar for the Cohesion Policy of the European Commission (EC) for the period 2014-2020. According to McCann (2015), S3 rationale fitted very well with the European Union (EU) Cohesion Policy due to two reasons. Firstly, it provided a policy prioritisation framework in line with the Europe 2020 strategy. Secondly, it followed a "place-based" logic, like the Cohesion Policy did. The place-based approach assumes that policy priorities should vary between different types of regions. It also suggests that regional policies should build on local capabilities and promote innovative strategies, based on local and non-local actors and knowledge (Rodrik 2005; Barca et al., 2012). This is what S3 do when applying a bottom-up approach such as the entrepreneurial discovery process.

The S3 approach also stresses the importance of a coherent design of regional strategies, based on the active participation of key stakeholders. This is quite a novelty with regard to regional innovation policies because, as pointed out by Uyarra (2010), Evolutionary scholars are usually biased towards normative analysis (what policymakers ought to do), disregarding the positive analysis (i.e. what policymakers actually do). S3 also refers to regional structural change and path development and transformation (Foray 2014). As noted by authors like Boschma and Lambooy (1999) and Neffke et al. (2011), the location of emerging industries is not a random process; existing industrial paths explain the new paths. This "related variety" or "related diversification" pertains to the existence of knowledge spillovers from existing sectors to new ones (Frenken et al. 2007; Boschma and Iammarino 2009). From the regional innovation policy perspective, the previous concepts and studies comprise a very useful instrument in order to prioritise industries or technologies with high potential.

\section{THE CONTENTS OF THIS BOOK}

The present book has as its standpoint the research activities developed by academics from different European institutions, which benefited from 
the support of the Jean Monnet project "EURIPER" (EU Regional and Innovation Policies and Peripheral Regions). This project, which took place between 2017 and 2019, was funded by the EC, coordinated by the University of Santiago de Compostela in Galicia (Spain), and enjoyed the participation of researchers from Norway, Italy, Poland, Germany and Denmark.

This book is composed of twelve chapters, which discuss regional innovation policies combining theoretical and empirical analyses. The chapters are organised in three main parts. The first part focuses on the foundations of regional innovation policies and it comprises four chapters. These chapters deal with interesting issues concerning regional innovation policies, such as regional path transformation, place-based strategies, learning policy and regional autonomy. The second part of the book (made up of four chapters) addresses the role of EU institutions in the promotion of regional development and innovation, as well as the combination of cohesion and competitiveness goals. The third part of the book presents four case studies of the regional innovation systems and policies of non-core European regions: Galicia (Spain), Apulia (Italy), Malopolska (Poland) and Agder (Norway).

The contents and contributions of each chapter are briefly described below.

Bjørn T. Asheim, Arne Isaksen and Michaela Trippl discuss the role of the RIS approach in contemporary regional policy. They pose two insightful questions: is the regional level still relevant for policymaking in a globalised world and is the RIS approach continuing to be a powerful tool for designing and implementing regional innovation policies directed towards promoting transformative changes? The chapter also addresses the transformations of regional innovation policy during three sequential frames (research and development [R\&D], innovation system and transformative change). The authors illustrate the discussion about RIS dynamics with compelling examples of regional innovation policies in Europe.

Next, Robert Hassink contributes to the understanding of place-based regional policies by strengthening the conceptualisation of place. This debate is more relevant within a context of economic and political instability, with growing populism, particularly in old industrial and rural areas (e.g. the USA). This instability may be related to uneven regional development in three domains: economic, social and recognition of inequalities. The author asks what regional places are in existence and whether they are still relevant in these unstable circumstances. This chapter discusses a placeneutral policy approach, which emphasises agglomeration economies for regional economic development, and a place-based policy approach, which 
consists of tailor-made policies. It also aims at a better understanding and improving of place-based policies.

In Chapter 3, Ainhoa Arrona, James Karlsen and Miren Larrea reflect on policy learning, focusing on the role of researchers. Policy learning is one mechanism for explaining policy changes and evolution. The chapter deals with issues such as what policy learning is, who is learning, what they are learning and the result of the learning process. Policy learning is more relevant within the context of responsible innovation, which addresses societal goals in a way that is socially desirable. This requires a change in the rationale of innovation policies, which affects policymakers as well as researchers.

This chapter addresses responsible innovation within regional innovation policies, based on in-depth interviews with policymakers in the Basque Country. The authors depart from the idea that policymakers do not always have the absorptive capacity required to implement policy recommendations delivered by researchers. However, they argue that, behind the low level of effectiveness, lies the need of a better understanding of the policy process by researchers, as much as the need of capabilities by policymakers. The chapter approaches this issue, providing a framework to better understand the policy process and how research can be relevant to improve the interaction. This framework is the action research for territorial development, which is developed in the regional innovation policy field. It proposes knowledge co-generation between policymakers and researchers as a specific form of policy learning, contributing to improve interactions and promote learning.

In the following chapter, Elisabeth Baier and Andrea Zenker discuss the interrelation between regional autonomy and innovation policies across Europe. Regional innovation policymaking is determined by different rationales, institutional structures and framework conditions. The varying degrees of autonomy for regional innovation policy depend on several aspects, such as decision-making power, budgetary responsibility, and region-specific technological and institutional trajectories. These aspects are shaped by different governance levels. The authors use a dynamic perspective within the innovation system framework approach, contributing to the conceptual and the policy-oriented dimensions. The chapter provides a conceptualisation and operationalisation of regional autonomy, proposing an empirical approach to describe and measure regional autonomy through a set of indicators that includes the role of EU funding and national constitutional settings. It also raises the question whether regions with higher degrees of autonomy have better conditions for designing and implementing territory-specific innovation policies. Moreover, the chapter analyses transformation processes concerning regional autonomy, 
which are mainly triggered by policies on the supra-national level, such as regional cohesion and economic development policy in the EU.

In Chapter 5, Cristina Ares provides an overview of the EU's Regional Development Policy or Cohesion Policy, and its transformations over time. The EU shows socioeconomic heterogeneity at the regional level, which has increased with the accession of new Member States from the 1980s. The reason for launching the Cohesion Policy was the willingness to compensate the less-favoured regions for the adaptation to the single market. However, the EU's Cohesion Policy has changed over time, and mainly since the beginning of the twenty-first century. The main changes are related to the accession of Southern and Eastern Member States, the limited size of the EU budget, and the Great Recession. Moreover, policy innovations have been introduced, with the aim of better investing EU funding. In this sense, S3 have become key instruments. This chapter underlines that the main change in policy rationale has been the progressive substitution of compensation logic based on helping less-favoured regions to converge, for the rationale of enhancing the competitiveness of the EU as a whole by means of regional development through innovation. This change involves investing more common structural budget in those territories where more results can be achieved. Other current trends in the EU's Cohesion Policy are related to underline the contextual factors of each region. Thus, the ERDP (European Regional Development Policy) has moved towards more comprehensive and well-timed strategies for regional development, and more integrated approaches, and to regionally differentiated investments and policy responses. This reorientation is problematic from the point of view of political equality and consequently EU discontent. The chapter supports more place-sensitive policies and empowerment of regional and local representatives in policy and investment prioritising.

Next, María del Carmen Sánchez-Carreira approaches the foundation and evolution of the EU's innovation policy over time, focusing on its key moments, rationales, objectives, tools and trends. Moreover, she tackles the regional perspective within the innovation policy. Traditionally the policy has been focused on research, according to the linear model of innovation. However, innovation has been gradually introduced and a systemic approach emerges. The EU's innovation policy is characterised by a multilevel model and the regions have increasingly become relevant actors in innovation policies. Among other actions, the Framework Programmes (FPs) and the European Structural Funds underline this development. The EU's innovation policy, and mainly the FPs, have hardly considered the territorial dimension, economic development or innovation level of the regions. Several attempts to include some element of cohesion in the policy have been made over time, through different tools. This chapter also 
deals with the links between EU regional and innovation policies, from their background to the current S3. It concludes that there is considerable potential for leveraging synergies between cohesion policy and innovation policy, as well as among other EC policies, despite the presence of challenges and risks for regional cohesion.

In Chapter 7, Óscar Rodil-Marzábal and Xavier Vence-Deza contribute to reopen the debate about regional convergence and the drivers of regional growth. The EU has been characterised by stages of increasing regional disparities in past decades, as well as since the Great Recession. Despite the diverse nature of factors explaining these differences, innovation is pinpointed as a key determinant. Thus, this chapter focuses on the role of innovative capacity in the growth performance of different regions in the Economic and Monetary Union (EMU) from the introduction of the Euro to the present. It also seeks to identify the relevance of different components of the RIS in the evolution of regional disparities. The authors analyse the growth patterns of the EMU regions considering differences regarding innovation and its effects on economic growth. This is a way to assess whether deeper integration has shown real capacity to promote territorial cohesion and moderate regional inequalities. The empirical study shows a positive association between innovation performance and economic growth. The findings also confirm that innovation performance should be considered in a complex and systemic framework where business plays a key role. Evidence of increasing regional disparities in parallel with deeper EU integration is a challenge both for economic growth theories and for policymakers. In this sense, the objective of boosting European economic growth is highly dependent on improving capabilities and reinforcing complementarities among all RIS components. Likewise, the objective of a more cohesive EU requires reinforcement of the RIS of all European regions. The chapter suggests that policies prioritise business capabilities in R\&D and non-R\&D innovation activities, as well as promotion of linkages between public and private agents.

In the following chapter, Pedro Varela-Vázquez and Manuel GonzálezLópez analyse the effects of the 6th and 7th Framework Programmes in regional innovation and scientific performance. The geographical distribution of project coordination and participation shows a high concentration in few hubs across Europe. This fact is coherent with the allocation criteria of the FPs, which are mainly based on scientific excellence and industrial leadership. This geographical concentration of projects has implications on regional cohesion, because it leads to increased regional differences in innovation and scientific performance, as well as in long-term economic growth. Empirical evidence highlights the positive role played by coordination and participation in projects to foster innovation and scientific 
outcomes. Coordination of projects is more effective in encouraging innovation in less-developed regions than in developed regions, while the opposite happens with scientific publications. Coordination of projects is also more effective in middle-income regions regarding both innovation and scientific performance. Participation in projects shows the highest impact in less-developed regions.

Next, Manuel González-López presents the case study of the innovation system and policies of Galicia, a European region in Northwest Spain. Galicia, which owns relevant legal and political competences on industrial and innovation policies, has progressively built an institutional set-up to support innovation and so to articulate its innovation system. Nevertheless, many structural weaknesses persist, which explains the relatively poor innovation performance of the region in comparison with the EU average. The late 2000s economic crisis, which hit particularly hard in southern European economies, also explains the difficulties involved here in improving innovation performance. All in all, the Galician economic structure has not experienced relevant changes and a conservative pattern has dominated over the last two decades.

In Chapter 10, Ivano Dileo and Francesco Losurdo analyse the evolution of regional innovation policies in the peripheral region of Apulia (Italy). This chapter focuses on legal and institutional frameworks, actions and instruments implemented over the last four EU planning periods. It attempts to understand how to overcome the old policy innovation approach towards the Research and Innovation Strategies for Smart Specialisation (RIS3) model, avoiding some identified risks. The authors present the strengths and weaknesses of the Apulia Research and Innovation (R\&I) system and policy, with a special focus on human resources, the fragmentation of research activities and the crisis in traditional manufacturing. Nevertheless, areas such as mechatronics, aerospace, ICT (Information and Communications Technology) and start-ups have created new opportunities to expand R\&I activities and increase the rate of skilled human capital. The involvement of local actors and the role of universities, as well as the effort to foster university-industry interaction, underline these developments. The chapter supports the need for new place-based and territorial-oriented approaches.

In the penultimate chapter, Marta Gancarczyk, Marta Najda-Janoszka and Jacek Gancarczyk analyse the evolution of the regional innovation system and policies in Malopolska (Poland) as a learning process. They use a positive perspective to present policy characteristics vis-à-vis the evolution of the Malopolska innovation system after Poland's accession to the EU in 2004. This chapter presents the real processes of formulating, adjusting and implementing innovation policies, including objectives, 
activities, assessment measures and budgets. It focuses on the dynamics of the innovation system, changes in the innovation policy regarding the regional specialisation, support for entrepreneurial discovery and innovation to open a new development path, and types of learning that stimulated the evolution of the regional innovation policies. Institutional mechanisms of learning were identified as the major drivers of the evolution of Malopolska's innovation policies. The authors' findings point to the increasingly positive potential of Malopolska's innovation system (input characteristics) and its less positive but improving performance (output characteristics). Its industrial specialisation evolved from an unfocused approach to combination of the dominant knowledge base and industries of new opportunities, following the SS concept. Policy measures and budgets increasingly targeted entrepreneurship support. This chapter proposes strengthening the interaction and synergies between the dominant and emerging areas of specialisation, and enhancing the collaborative links among businesses, as well as among businesses and academia.

Finally, Roger Normann, Sissel Strickert and Jon P. Knudsen discuss the emergence of a new set of innovation policies in the region of Agder (Norway), within the context of RIS3 as a dominating paradigm in Europe and a significant regional reform model in Norway. This case is unusual, because Norway does not belong to the EU. The chapter takes account of the status for these processes and asks which steps lie ahead for innovation policy development and learning based on developments in that region. It seeks to identify some of the key features of regional innovation policy, as well as the key challenges. Moreover, it raises the question of how the Agder region's response to RIS3 can be explained. This region had only a symbolic response to RIS3, a fact that may surprise, given that it had proven itself to be a place-based leadership capable of executing and realising complex innovation policy goals. The authors consider the existence of different types of rationales for choosing whether to implement a new policy at the regional level. Access to structural funds is one of the drivers of RIS3 as a policy in the EU. Since Norwegian regions do not have access to EU structural funding, this incentive is missing. RIS3 development was neither required nor encouraged by the national government, while Norwegian regions became increasingly occupied with internal processes, managing the planning and execution of the reform. In addition, cuts in national budgets mean scarcer resources for R\&D. RIS3 in Agder had potential to be a useful amendment to existing ways of working, planning, developing and executing a new set of effective regional innovation policies. 


\section{ACKNOWLEDGEMENT}

This book has received support from the project EURIPER (EU Regional and Innovation Policies and Peripheral Regions), funded by the European Commission under the Jean Monnet Projects Action of the Erasmus+ Programme (Project Reference: 587410-EPP-1-2017-1-ES-EPPJMO -PROJECT).

\section{REFERENCES}

Asheim, B.T. (1996). Industrial districts as "learning regions": a condition for prosperity. European Planning Studies, 4(4), 379-400.

Asheim, B.T. (2019). Smart specialisation, innovation policy and regional innovation systems: what about new path development in less innovative regions? Innovation: The European Journal of Social Science Research, 32(1), 8-25, DOI: 10.1080/13511610.2018.1491001

Asheim, B.T., and M.S. Gertler (2005). The geography of innovation: regional innovation systems. In The Oxford handbook of innovation, edited by J. Fagerberg, D. Mowery and R. Nelson, 291-317. Oxford: Oxford University Press.

Asheim, B.T., and A. Isaksen (1997). Location, agglomeration and innovation: towards regional innovation systems in Norway? European Planning Studies, 5(3), 299-330.

Barca, F., P. McCann and A. Rodríguez-Pose (2012). The case for regional development intervention: place-based versus place-neutral approaches. Journal of Regional Science, 52(1), 134-52.

Becattini, G. (1990). The Marshallian industrial district as a socio-economic notion. In Industrial districts and inter-firm co-operation in Italy, edited by F. Pyke, G. Becattini and W. Sengenberger, 37-51. Geneva: International Labour Organization.

Boschma, R., and S. Iammarino (2009). Related variety, trade linkages, and regional growth in Italy. Economic Geography, 85(3), 289-311.

Boschma, R.A., and J.G. Lambooy (1999). Evolutionary economics and economic geography. Journal of Evolutionary Economics, 9(4), 411-29.

Cooke, P. (1992). Regional innovation systems: competitive regulation in the new Europe. Geoforum, 23(3), 365-82.

Cooke, P. (2001). Regional innovation systems, clusters, and the knowledge economy. Industrial and Corporate Change, 10(4), 945-74.

Cooke, P., M.G. Uranga and G. Etxebarria (1997). Regional innovation systems: institutional and organisational dimensions. Research Policy, 26(4-5), 475-91.

Dosi, G., and R.R. Nelson (1994). An introduction to evolutionary theories in economics. Journal of Evolutionary Economics, 4(3), 153-72.

Edquist, C. (ed.) (1997). Systems of innovation: technologies, institutions and organizations. London: Pinter.

Foray, D. (2014). Smart specialisation: opportunities and challenges for regional innovation policy. New York, NY: Routledge.

Frenken, K., F. Van Oort and T. Verburg (2007). Related variety, unrelated variety and regional economic growth. Regional Studies, 41(5), 685-97. 
González-López, M., B.T. Asheim and M.D.C. Sánchez-Carreira (2019). New insights on regional innovation policies. Innovation: The European Journal of Social Science Research, 32(1), 1-7, DOI: 10.1080/13511610.2018.1537121

Howells, J. (1999). Regional systems of innovation. In Innovation policy in a global economy, edited by D. Archibugi, J. Howells and J. Michie, 67-93. Cambridge: Cambridge University Press.

Lundvall, B.-Å. (1992). National systems of innovation: towards a theory of innovation and interactive learning. London: Pinter.

Lundvall, B.-Å, and B. Johnson (1994). The learning economy. Journal of Industry Studies, 1(2), 23-42.

McCann, P. (2015). The regional and urban policy of the European Union: cohesion, results-orientation and smart specialisation. Cheltenham, UK and Northampton, MA, USA: Edward Elgar Publishing.

Metcalfe, J.S., and L. Georghiou (1997). Equilibrium and evolutionary foundations of technology policy. CRIC Discussion Paper No. 3. Centre for Research on Innovation and Competition, University of Manchester.

Morgan, K. (1997). The learning region: institutions, innovation and regional renewal. Regional Studies, 31(5), 491-503.

Neffke, F., M. Henning and R. Boschma (2011). How do regions diversify over time? Industry relatedness and the development of new growth paths in regions. Economic Geography, 87(3), 237-65.

Nelson, R.R., and S.G. Winter (1982). An evolutionary theory of economic change. Cambridge: Belknap.

Porter, M.E. (2000). Location, competition, and economic development: local clusters in a global economy. Economic Development Quarterly, 14(1), 15-34.

Rodrik, D. (2005). Growth strategies. In Handbook of economic growth, edited by P. Aghion and S. Durlauf, 967-1014. Amsterdam: Elsevier.

Scott, A.J. (1988). Flexible production systems and regional development: the rise of new industrial spaces in North America and Western Europe. International Journal of Urban and Regional Research, 12(2), 171-86.

Storper, M., and B. Harrison (1991). Flexibility, hierarchy and regional development: the changing structure of industrial production systems and their forms of governance in the 1990s. Research Policy, 20(5), 407-22.

Uyarra, E. (2010). What is evolutionary about "regional systems of innovation"? Implications for regional policy. Journal of Evolutionary Economics, 20(1), 115-37, DOI: 10.1007/s00191-009-0135-y 